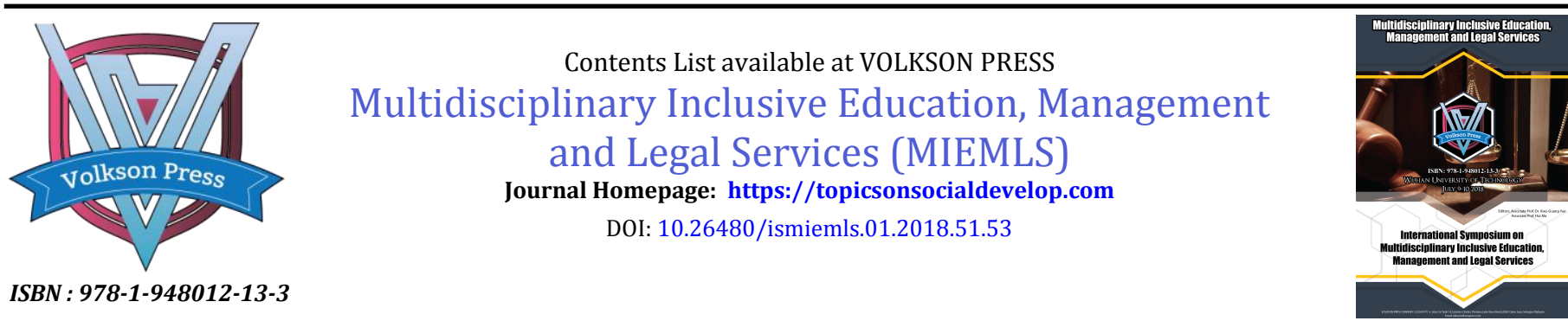

\title{
CURRICULUM CONSTRUCTION OF PRINCIPLES AND APPLICATIONS OF EMBEDDED SYSTEM IN MEDICAL COLLEGE BASED ON CDIO
}

\author{
Boyu Si*, Baodan Bai, Lijun Hao, Xiaoou Li \\ School of Medical Instrument, Shanghai University of Medicine \& Health Sciences, 257 Tianxiong Road, Shanghai, China \\ *Corresponding Author Email: siby@sumhs.edu.cn
}

This is an open access article distributed under the Creative Commons Attribution License, which permits unrestricted use, distribution, and reproduction in any medium, provided the original work is properly cited.

\section{ARTICLE DETAILS}

Article History:

Received 26 June 2018

Accepted 2 July 2018

Available online 1 August 2018

\begin{abstract}
In this paper, an integration of theory and practice with the CDIO model as the core of the embedded system curriculum system, including three main contents: embedded system principle course content system, embedded system experiment platform examples, embedded system modularization experiment, is built in the Biomedical Engineering major of Shanghai University of Medicine \& Health Sciences. The CDIO project teaching can cultivate students' comprehensive application ability. It can link with the employers better. In addition, through the construction of the experimental platform of embedded system teaching and scientific research, the experimental teaching quality of the embedded system course is improved. At the same time, it also provides favorable conditions for students to participate in various kinds of electronic competitions and teachers to carry out scientific research activities. It greatly promotes the reform of medical engineering education in our school. The training quality of applied undergraduate medical talents in the medical universities has been promoted.
\end{abstract}

\section{KEYWORDS}

Embedded System, CDIO, Application-oriented undergraduate.

\section{INTRODUCTION}

Since the enrollment of the biomedical engineering students in Shanghai University of Medicine \& Health Sciences in 2015, the CDIO teaching mode has been explicitly adopted to carry out teaching and personnel training. In the past 4 years, in the process of training biomedical engineering professionals, based on the CDIO teaching model, students have been greatly improved in both individual strategy and team cooperation in practice, especially in all kinds of professional competitions [1]. Based on a study, the principle and application of embedded system is a professional course, which is for the senior student majoring in biomedical engineering. After studying a series of professional courses such as microcomputer principle, MCU, digital circuit and so on, the students have mastered a certain computer hardware technology, and then study embedded system to provide better practical forging opportunities for their future work in the design of medical equipment and system management [2]. Therefore, it is necessary to meet the dual needs of the theory and practice of the students based on CDIO in the course of the principle and application of embedded system related to the medical instruments. This paper will discuss the construction plan of the embedded system course based on the CDIO, which consists of the teaching idea and teaching goal, the construction plan, the experiment design and the management of the embedded system principle and application course for medical college.

\section{THE CONSTRUCTION IDEA AND GOAL}

\subsection{The Construction Idea}

Based on the Shanghai wearable medical technology and equipment engineering research Center, the major construction, discipline construction and curriculum construction are coordinated. Adhere to the CDIO teaching mode driven by engineering projects as the training target of the biomedical engineering specialty, take the student as the oriented, perfect the core of the knowledge imparting, the ability training, the quality improvement, closely fit the subject development front in the course content, the teaching method, the experimental equipment and the integration of theory and practice, and continue to raise the level of education. construction of talent team, through the introduction of talent, training and employment, and hiring the part-time stuff and other measures to improve the overall strength of the whole course teaching team, to build a theory and practice integrated teaching team with advanced teaching method and rational knowledge structure [3].

Deepening the reform of experimental teaching, putting forward the experimental teaching system of "stage training, multi-level promotion and all-round training", training the students' practical ability, exploring the reform ideas of theory and practice flexible teaching, strengthening the cultivation of students' self-learning ability, widening the students' research path and cultivating their team spirit of the needs for adapting the society. We should focus on cultivating students' ability of innovation engineering, practice and comprehensive application, so as to achieve the goal of "thick foundation, wide caliber, strong ability and high quality".

\subsection{The Construction Goal}

The overall goal of the construction is to introduce the CDIO teaching practice model to meet the actual needs of the integrated curriculum, and to simulate the work scene of the embedded system software and hardware development according to the project module developed of the embedded system.

The specific objectives are as follows: (1) to design the theory and application of the embedded system principle and application in close combination with the characteristics of Shanghai University of Medicine \& Health Sciences in the field of medical instruments, (2) build a hardware development platform based on ARM Cortex, (3) build an embedded system virtual experiment platform based on the Proteus simulation software.

\section{THE CONSTRUCTION PLAN}

The course construction of "principle and application of embedded system" based on CDIO includes three main contents: embedded system principle course content system, embedded system experiment platform examples, embedded system modularization experiment. 


\subsection{The Embedded System Principle Course System}

The embedded system principle and application course of Biomedical Engineering in our school is based on the popular embedded microprocessor and embedded operating system of ARM architecture at home and abroad. The design and application of embedded hardware system architecture, embedded microprocessor and system core circuit interface, as well as embedded software architecture, the main stream embedded operating system and its application programming and transplantation and other related knowledge and technology are introduced in detail.

The content of embedded system development and application is very complicated. It involves many professional knowledges such as computer, electronics, automatic control, and so on. It is unrealistic to make students fully master the whole knowledge of embedded system design in very limited class time. Therefore, the real meaning of teaching embedded system is to enable students to master the basic knowledge and development methods of embedded system design. Practice is an important link in the design of embedded system. Through practice, students can master the specific link of embedded system development and accumulate useful development experience.

\subsection{The Embedded System Experiment Platform Examples}

The overall goal of the construction is to introduce the CDIO teaching practice model to meet the actual needs of the integrated curriculum, and to simulate the work scene of the embedded system software and hardware development according to the project module developed of the embedded system.

The embedded system teaching experiment platform takes 32-bit ARM Cortex-A9 processor as the main control chip, the frequency is as high as $1.4 \mathrm{GHz}$, and runs the most mainstream Android system in the current embedded system teaching, and there is rich open source code and application software. In the process of learning, students can learn the basic methods of research and design of embedded system products from many aspects, such as the underlying architecture of the chip, the middle layer of the system and the upper application. Students can not only understand the development trend of embedded technology at the same time, but also grasp the core technology of embedded system at a deeper level. The specific content and time assignment are shown in Table 1.

Table 1: The Embedded System Experiment Platform Examples

\begin{tabular}{|c|c|c|}
\hline & Experiment Content & $\begin{array}{l}\text { School } \\
\text { Hours }\end{array}$ \\
\hline 1 & $\begin{array}{l}\text { Application Layout of embedded system and } \\
\text { introduction of common controls }\end{array}$ & 3 \\
\hline 2 & Introduction and example of Intent and Activity & 1 \\
\hline 3 & Introduction and example of Dialog & 1 \\
\hline 4 & Introduction and example of Menu & 1 \\
\hline 5 & Introduction and example of List View & 1 \\
\hline
\end{tabular}

\subsection{The Embedded System Modularization Experiment}

The overall goal of the construction is to introduce the CDIO teaching practice model to meet the actual needs of the integrated curriculum, and to simulate the work scene of the embedded system software and hardware development according to the project module developed of the embedded system.

The embedded system modularization experiment is designed for students to better understand and master the embedded product development process. In scientific research and engineering practice, it is often necessary to use embedded systems to develop product prototypes, which are widely used in intelligent medical electronics, industrial automation, aerospace and other industrial fields. Students can develop and debug embedded hardware, embedded device driver and embedded application software based on a variety of embedded system function modules and simulate the development of research activities in the CDIO project model. The specific modules and the time assignment are shown in Table 2.

Table 2: The Embedded System Modularization Experiment

\begin{tabular}{|llc|}
\hline & Experiment Content & School Hours \\
\hline 1 & I/O Control & 2 \\
2 & Touch Screen & 2 \\
3 & Camera & 2 \\
4 & SD Card Reader & 2 \\
5 & USB OTG & 2 \\
6 & VGA Output & 2 \\
7 & 3D Graphic & 2 \\
8 & WIFI Communication & 2 \\
9 & GPS & 2 \\
10 & Bluetooth & 2 \\
11 & Mobile Communication & 2 \\
12 & G-sensor & 2 \\
\hline
\end{tabular}

\section{DISCUSSION}

The construction of embedded system course for Biomedical Engineering in medical school may be faced with more difficulties, especially the combination of curriculum content and medical school conditions, closely related to the subject of medical instruments, and perfect the practical teaching quality of the "embedded system principle and application" course. We believe that the following aspects should be improved:

\subsection{Gradually Improve the Environment and Conditions of the Experiment}

With the further development of the biomedical engineering major, the number of enrollments increases year by year, and the shortage of embedded system experiment equipment becomes obvious. For example, the laboratory area is small, the number of laboratory equipment is insufficient, and many other courses occupy the laboratory time. These circumstances objectively affect the enthusiasm of students in learning the principles and applications of embedded systems and the development of the whole CDIO project. Therefore, in terms of hardware conditions, we must strengthen the collation and planning of laboratories, and make rational use and distribution of existing resources. In the purchase of new equipment, it is necessary to strengthen the feasibility and reasonableness of the demonstration, to ensure the urgent need for the urgent procurement of teaching and scientific research equipment, optimize the utilization of the laboratory, while avoiding the time conflict of the course occupancy experiments, but also as much as possible to reduce idle equipment and waste of resources.

\subsection{Strengthening the Technical Level Construction of the Teaching Team}

Introduce teaching practice talents at different levels. Through the formulation of relevant policies, the teaching contingent of high level and highly educated persons with high degree of education, such as professors and doctorate, is introduced from home and abroad and enterprises and institutions to integrate the curriculum construction with the construction of the subject and the subject closely. Encourage young teachers to go deep into enterprises to carry out production, teaching and research work, fully exercise their practical ability, and strive to become excellent teaching and scientific research talents.

Strengthen the training of team members. In order to improve the professional quality of the whole teaching team, young and middle-aged teachers are encouraged to take active part in on-the-job training. To establish cooperative relationship with the universities which belongs to the national ministry of education and high-tech enterprises, appoint teaching team teachers to visit, study, listen to lectures and exchange experiences.

\section{CONCLUSIONS}

In order to solve the problem of training medical engineering talents in medical colleges and universities with a relatively weak practical ability, 
through in-depth investigation, the integration of theory and practice with the CDIO model as the core of the embedded system curriculum system is

Medicine \& Health Sciences. The CDIO project teaching can cultivate students' comprehensive application ability. It can better link with the employers. In addition, through the construction of the experimental platform of embedded system teaching and scientific research, the experimental teaching quality of the embedded system course is improved. At the same time, it also provides favorable conditions for students to participate in various kinds of electronic competitions and teachers to carry out scientific research activities. It greatly promotes the reform of medical engineering education in our school. The training quality of applied undergraduate medical talents in the medical universities has been promoted.

\section{ACKNOWLEDGMENTS}

This paper is supported by the Course Construction Project of Shanghai University of Medicine \& Health Sciences 'Principle and Application of Embedded System' (2018). built in the Biomedical Engineering major of Shanghai University of

\section{REFERENCES}

[1] Haupt, G., Webber-Youngman, R.C.W. 2018. Engineering education - An Integrated Problem-solving Framework for Disciplinespecific Professional Development in Mining Engineering. Journal of the Southern African Institute of Mining and Metallurgy, 118, 27-37.

[2] Kabukcuoglu, S. 2017. Calretinin Expression in Endometriosis. Is calretinin positive tubal epithelium origin of fallopian tube carcinoma. European Journal of Gynaecological Oncology, 38, 905-909.

[3] Edstrom, K. 2018. Academic and Professional Values in Engineering Education - Engaging with History to Explore a Persistent Tension. Engineering Studies, 10, 38-65. 